\title{
The birth of science
}

\author{
The Emergence of a Scientific Culture: \\ Science and the Shaping of Modernity \\ 1210-1685 \\ by Stephen Gaukroger \\ Oxford University Press: 2006. 576 pp. \\ $\notin 35, \$ 65$
}

\section{Peter Dear}

Why do we look to science to guide our lives in the modern world? That most of us do so is manifest from an examination of the cultural and political history of the past century. This point is made very early on by Stephen Gaukroger in his new book The Emergence of a Scientific Culture, when he quotes Jawaharlal Nehru. But what does it mean, and how, historically, did it come to be the case? Not surprisingly, Gaukroger's attempts to resolve such a grand issue are, literally, weighty, as this volume constitutes the first of a projected five. It is not an easy question to answer.

By starting the story in thirteenth-century Latin Europe, Gaukroger presents a world in which theology, not 'natural philosophy', was regarded as the 'queen of the sciences'. He then traces how this gradually ceased to be the case, and natural philosophy, albeit of a new kind, displaced theology as the touchstone of cognitive propriety. By the end of the seventeenth century, many people were arguing that the standards and procedures of natural philosophy were appropriate models for all kinds of cognitive enquiry, including those involving theology and religion.

Gaukroger's big claim is that, although technical scientific endeavours and achievements have cropped up in various world cultures at different times, it was only in the European culture that formed in the seventeenth century that these advances became a continuous tradition. What made Europe different is that a new form of philosophical enquiry into nature took the lead in determining what were still the culturally dominant questions in Europe, namely those concerning religion. Far from separating itself from religion, European science at the time became the principal tool for underpinning it: understanding nature was the path towards knowledge of God. And having attained this status by the 1680 s, argues Gaukroger, science hasn't looked back since.

There are many complexities in the book's overall narrative. One is the relationship between modern science, which as a coherent, institutionalized endeavour is usually seen by historians (including Gaukroger) as having emerged in the nineteenth century, and the earlier field of natural philosophy. Natural philosophy since the thirteenth century had been centred on the works of Aristotle, and was defined as a contemplative intellectual pursuit aimed at providing causal accounts of natural phenomena. It explicitly eschewed practical ends, seeking only cognitive understanding.

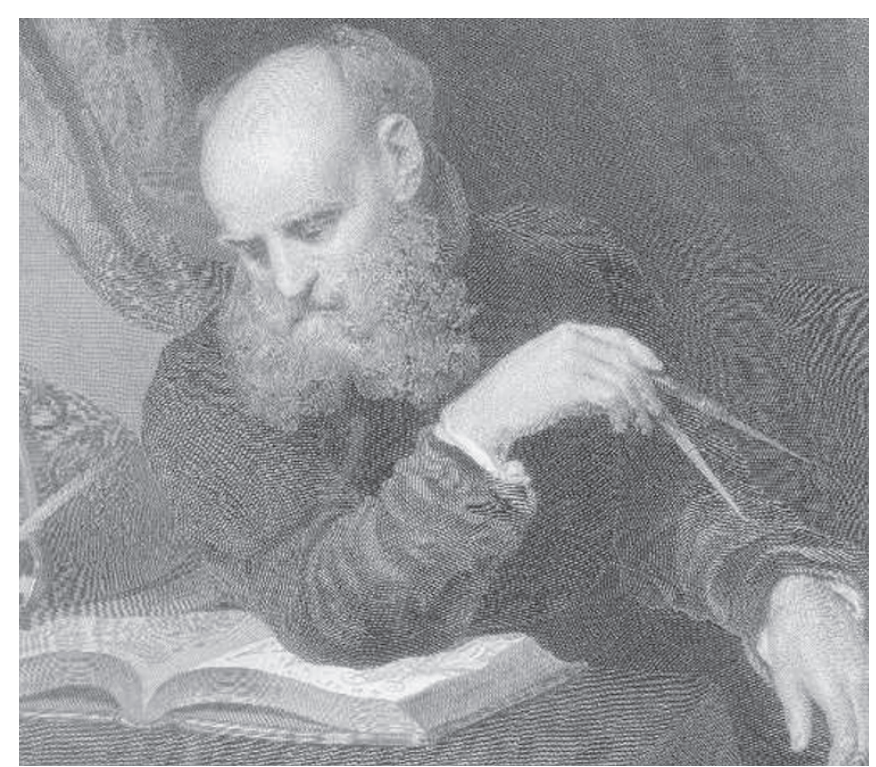

Galileo was central to the rise of a mathematical 'natural philosophy'.

The great changes of the seventeenth century that Gaukroger details involved a rejection of many features of aristotelian natural philosophy. In its place appeared a kind of natural philosophy that incorporated practical mathematical sciences (such as astronomy, mechanics and optics) and forms of 'mechanism' that offered explanations of macroscale phenomena in terms of the underlying structure

\section{SCIENCE BOOKS AWARD}

Judging for the Royal Society Prizes for Science Books is well under way. The longlist of books for the general prize includes a wider mix of popular science books than in previous years, with Giant Leaps by journalist John Perry of UK newspaper The Sun and Jack Challoner vying with Nobel laureate Eric Kandel's memoir In Search of Memory. The mysteries of the mind are also explored by Cordelia Fine in A Mind of its Own and Daniel Gilbert in Stumbling on Happiness. Adam Wishart's One in Three is a personal exploration of the biology and treatment of cancer. Current issues are represented by Robert Henson's The Rough Guide to Climate Change and TV tie-ins by The Science of Doctor Who by Paul Parsons. Established writers Matt Ridley (who wrote Francis Crick), Paul Davies (The Goldilocks Enigma) and Chris Stringer (Homo Britannicus) appear alongside newcomer Henry Nicholls (Lonesome George). Rock guitarist Brian May joined experienced astronomers Patrick Moore and Chris Lintott to write Bang!

This list will be whittled down to a shortlist of six, and the winners of both the general and the junior prizes will be announced on 15 May 2007.

www.royalsoc.ac.uk/sciencebooks of matter (atomistic or corpuscularian).

Figures such as Francis Bacon in the early seventeenth century further reconstructed the mission of natural philosophy by rejecting its aristotelian restriction to contemplative knowledge. They argued instead, in explicitly religious terms, that its proper role was precisely to produce control over nature for the practical benefit of mankind. Indeed, Gaukroger here makes a powerful case that this development formed part of a larger reconstruction of natural philosophy that related it more closely to moral philosophy. Other ancient Greek philosophers, he argues, had understood their task as one of determining how best to live in the world, with ideas about nature being subservient to that end.

In rejecting Aristotle, seventeenth-century natural philosophers revitalized that old ideal, and in doing so adopted a new persona, placing a premium on objectivity and trustworthiness that outshone dogmatic claims to knowledge of truth. The experimental philosophy of Robert Boyle and Isaac Newton, for example, set itself up as a model of disciplined enquiry to be emulated by the rest of society, rather as experimental philosophy owed much to legal practices. Whether the natural philosophers of the seventeenth century, with their great variety of commitments and approaches, should therefore be seen as scientists avant la lettre is a question that Gaukroger in effect defers.

Despite its sweeping chronological scope, Gaukroger's book focuses largely on prominent figures of the seventeenth century, including Johannes Kepler, Bacon, Galileo and René Descartes. Gaukroger provides an insightful analysis of their natural-philosophical ideas and arguments, paying special attention to the epistemological conceptions that each represented and developed.

The book's title uses the term 'scientific culture', but its content also reminds us of its author's accomplishments as a historian of philosophy. Why the changes that Gaukroger describes should have occurred in seventeenthcentury Europe remains largely unanswered, but this book contributes to the formulation and solution of that possibly intractable question, and promises even more in future volumes.

Peter Dear is in the Department of History, Cornell University, Ithaca, New York 14853, USA. 